\title{
II.6. Que se fosse para o mundo: Por uma curadoria ao avesso
}

\section{II.6. That it were for the world: Curating Inside-Out}

\section{Jessica Gogan}

\section{Resumo}

Com um desdobramento da minha tese de doutorado Curating Publics in Brazil: Experiment, Construct, Care (2016) e parte do estágio pós doutoral no Programa de Pós-Graduação em Estudos Contemporâneos das Artes (PPGCA) na Universidade Federal Fluminense (UFF) ${ }^{129}$, busca-se conceituar uma teoria/prática de uma curadoria ao avesso, ancorada em uma abordagem ecossistêmica do cuidado na contemporaneidade, entrelaçando as propostas de reviramento em prol do surgimento de um avesso, delineadas nas escritas de arte e psicanálise de Tania Rivera e de filosofia de Peter Pál Pelbart, com perspectivas críticas e clínicas que apontam para a proximidade como posicionamento ético e práticas contemporâneas experimentando com diversos dispositivos de arte-ação e modos de estar juntos. Este texto oferece um recorte desta pesquisa em processo.

Palavras chave: cuidado, clínica, pedagogia, curadoria, arte contemporânea.

\begin{abstract}
This article continues the work developed in my PhD thesis "Curating Publics in Brazil: Experiment, Construct, Care" (2016) and draws on current postdoctoral research in the Post Graduate Program in Contemporary Studies of the Arts (PPGCA) at the Universidade Federal Fluminense (UFF) to conceptualize a theory / practice of curating inside-out, anchored in an ecosystemic approach of care in the contemporary world, the writings of Tania Rivera (art and psychoanalysis) and Peter Pál Pelbart (philosophy), critical and clinical perspectives that point to proximity as an ethical position and contemporary practices experimenting with diverse apparatuses of art-action and ways of being together. This text offers a clipping of this in-process search.
\end{abstract}

Key words: care, clinic, pedagogy, curating, contemporary art.

\section{Que se fosse para o mundo: Por uma curadoria ao avesso}

É preciso, pois, examinar esses instrumentos de dominação e, em seguida, libertar cada um dos componentes do sistema da arte - a obra, o público, a crítica, o ensino, o museu, o próprio mercado nacional - para que, novamente juntos, possam servir como instrumento de aprofundamento de nossa realidade sócio-cultural e política. Só mediante um questionamento radical de cada um dos componentes do sistema da arte e da maneira como se relacionam entre si e na sociedade, poderemos libertar a arte latino-americana de sua dependência e, simultaneamente, ampliar seu campo de ação como instrumento de consciência revolucionária. Frederico Morais (1979: 14).

A psicanalista e crítica de arte Tania Rivera começa seu livro, $O$ avesso do imaginário: arte contemporânea e psicanálise, evocando a fita de Moebius. A

129 Sob orientação científica da Professora Doutora Tania Rivera. 
figura topológica subverte oposições binárias, apontando para a sua natureza contígua, enquanto descobrimos atravessando a fita que seus dois lados são, de fato, torções contínuas de uma fita só. O dentro é fora, e vice-versa, sugere um jogo metafórico constante de "reversão do eu e do mundo" (Rivera, 2013: 9).

Inaugurando seu conceito de artista como propositor, Lygia Clark, em Caminhando, 1963, utilizou a superfície aparentemente dupla da fita de Moebius para criar um "novo espaço tempo concreto" (1964), convidando o espectador/participante a cortar ao longo da fita, realizando suas próprias escolhas de direção, espessura etc. Uma revolução em sua prática, Caminhando é um momento-chave da vanguarda brasileira, deslocando a ênfase da arte como objeto para uma proposição de ação e experiência. Clark subverte as dobras fixas de aço da escultura de Max Bill da fita de Moebius, Unidade Tripardida, 1948-49, exposta na 1ª Bienal de São Paulo em 1951, para abrir-se ao outro e à indeterminação. Ao invés da formas concretas e opostas, há dobras e redobras, inseparáveis umas das outras e do processo em si, esboçando, como descreve Clark, um "itinerário interior fora de mim" (1965 in Rivera, 2008). A arte como ato possibilita a nos vermos no fazer caminhando, pensando, fazendo, cortando...

Assim como para as inversões dialógicas de arte e psicanálise de Rivera e as propostas cada vez mais terapêuticas de Clark, a fita de Moebius é uma metáfora chave para uma curadoria como prática ecossistêmica de arte, ética e educação na esfera pública - uma curadoria que caminha, pensa, corta e cuida entre as tensões experienciais de subversão de dicotomias: dentro e fora; teoria e prática; observação e participação. Tal curadoria explora a capacidade da arte de atuar como dispositivo epistemológico e ontológico. Ela nos convida a pôr em prática, como o filósofo Peter Pál Pelbart sugere, um modo de "dobrar de outra forma as forças do exterior," permitindo uma função estratégica e política que pode desencadear mutações generativas e subjetivas, além de uma redistribuição dos afetos (2013: 174). Estas dobras, como colocado pelo curador e crítico Frederico Morais na citação de abertura, poderão até atuar como "um instrumento de consciência revolucionária”. Embora publicado em 1979, a provocação de Morais para "libertar" e "questionar radicalmente" os componentes do sistema de arte e como eles se inter-relacionam para "aprofundar o conhecimento de nossa realidade sócio-cultural e política”, parece urgente em tempos de crescentes 
incertezas e precariedade global. O que conseguiríamos se reuníssemos artistas, educadores, curadores, pesquisadores, públicos e instituições em práticas horizontais de fazer, ouvir e refletir? Como poderíamos reconfigurar e nos permitir ser reconfigurados? Que novos entendimentos, possibilidades poéticas e contribuições sociais poderiam emergir desse processo?

Acontecendo entre e com artistas/obras/práticas, contextos e públicos, uma curadoria ao avesso busca viver e aprofundar essas questões. Seu fio condutor baseia-se no avesso dos paradigmas tradicionais ou mercadológicas, na busca por uma outra forma de curadoria a partir de sua raiz etimológica curare - cuidar/curar - reformulando-se como uma rede de aprendizado molecular derivado de um contágio de encontros - de ideias, práticas, pessoas e contextos - e um compromisso ético e ecossistêmico. Nesse sentido, a arte é tomada como espaço/tempo de produção de saberes e aprendizagem a ser ocupado ou melhor, movimentado coletivamente, "assumindo", como Hélio Oiticica defendia, o "experimental" como método (in Braga, 2008: 347-351).

O conceito de uma curadoria ao avesso é um desdobramento da análise tripartida das práticas do experimentar, construir e cuidar desenvolvida na minha tese de doutorado Curating Publics in Brazil: Experiment, Construct, Care (2016). A tese consistiu em três estudos de caso de engajamento social de arte, curadoria e educação situados em diferentes instituições de arte no Brasil das quais participei como coordenadora, pesquisadora ou curadora. Cada estudo foi ancorado em modos e práticas específicas - laboratório/experimentar, escola/construir, clínica/cuidar - e um contexto institucional particular: o Museu de Arte Moderna, Rio de Janeiro; Bienal de Arte Contemporânea do Mercosul, Porto Alegre; e o Museu de Arte Contemporânea de Niterói. A conclusão apontou um inventário de práticas emergindo dos desafios de cada situação, como um conjunto de "lições" contingentes, relacionais e contextuais projetado como ponto de partida para se conceber uma política curatorial artística-pedogógica-clínica fundamentada em uma práxis de experimentar, construir e cuidar. Se o experimental e o construtivo marcaram as práticas das vanguardas e alternativas no século 20 na arte, curadoria e educação, embora nem sempre tenha havido diálogo entre esses campos, podemos identificar o cuidado como dimensão que emerge no contemporâneo exigindo um novo tipo de conectividade entre essas práticas como um substrato de cumplicidade ético- 
afetiva. Assim como desobramento, busca-se conceituar uma teoria/prática de uma curadoria ao avesso, ancorada em uma abordagem ecossistêmica do cuidado na contemporaneidade, entrelaçando as propostas de reviramento em prol do surgimento de um avesso, delineadas nas escritas de arte e psicanálise de Rivera e de filosofia de Pelbart, com perspectivas críticas e clínicas que apontam para a proximidade como posicionamento ético e praticas contemporâneas experimentando com diversos dispositivos de arteação e modos de estar juntos. Este artigo oferece um recorte desta pesquisa em processo.

\section{Laboratórios, escolas, clinicas: modos e praxes para uma curadoria ao avesso}

Em seu projeto de exposição e intervenções em 1999, na Antuérpia, intitulado Laboratorium, os curadores Hans Ulrich Obrist e Barbara Vanderlinden poderiam ter resumindo as experimentações curatoriais dos anos precendentes em sua máxima "Laboratório é a resposta. Qual é a questão?" (2001). Na última década essa máxima poderia ter sido "A escola é a resposta", se lançamos nosso olhar sobre diversos exemplos curatoriais e artísticos usando formatos pedagógicos e não-expositivos, não como iniciativa complementar, mas como proposta central ${ }^{130}$. Talvez a próxima máxima pudesse ser "a clínica é a resposta", respondendo ao interesse emergente em questões de cuidado ${ }^{131}$. Cada uma, claro, não é uma resposta, mas sim um modo que sanciona e conota um conjunto de práticas: experimentação, investigação, teste; conhecimento, aprendizagem, instrução coletiva; e cura, escuta, diagnóstico; entre outras possibilidades.

Esses conceitos e práticas certamente não são novos. O laboratório como modelo emprestado emergiu no final do século XIX com, por exemplo, a Escola Laboratório do filosofo e educador John Dewey em Chicago EUA

\footnotetext{
${ }^{130}$ Alguns exemplos: a escola de performance Arte de Conducta da artista Tania Bruguera na Havana (2002 - 2009); o projeto não realizado de uma escola de arte para a bienal Manifesta 6 em Nicósia, Chipre (2006) e sua publicação Notes for an Artschool, e The Para-education Department, um grupo de estudo e seminário organizado pela artista Sarah Pierce e curadora Annie Fletcher em Rotterdam (2005). No Brasil destacam-se as 'escolas' pedagógica-artísticas da Bienal do Mercosul (2007 - 2013) e os projetos artísticos Café Educativo de Jorge Menna Barreto (2007 - ) e Escola da Floresta de Fabio Tremonte (2016 - ) entre outros.

${ }^{131}$ Exemplos variam desde do Skills Exchange: Urban Transformation and the Politics of Care compondo projetos comissionados com artistas, arquitetos, agentes de saúde e pessoas de terceira idade realizados por Janna Graham no Serpentine Gallery em Londres (2007 - 2013) até as praticas clínicas-artísticas de criar espaços públicos de escuta mutua da artista Graziela Kunsch e do psicanalista Daniel Guimarães em São Paulo e Rio de Janeiro (2016 - ).
} 
(1896 - 1899). Ressurge ao longo do século seguinte em contextos diversos tais como as experiências de Alexander Dorner na direção do Landesmuseum em Hannover, Alemanha, nos anos 1920 e sua idéia do museu como uma "máquina viva" e um "laboratório" (Obrist e Acconci in Noeve, 2001: 150-151) ou a Unidade Experimental inaugurada em 1969 pelos artistas Cildo Meirles, Luiz Alphonsus e Guilherme Vaz e Frederico Morais como laboratório pedagógico afiliado ao departamento de cursos do Museu de Arte Moderna no Rio de Janeiro, na época sob a coordenação de Morais (Gogan e Morais, 2017: 237).

Museus de arte e escolas têm sempre sido concebidos como coparceiros, em diversos casos a escola dando origem ao museu - School of the Art Institute of Chicago e o The Art Institute of Chicago nos EUA ou Escola de Belas Artes e Museu Nacional de Belas Artes no Brasil vêm à mente. Mas os museus também foram re-imaginados como escolas em si, como por exemplo a visão da arquiteta Lina Bo Bardi que anotou em 1960, enquanto diretora do novo Museu de Arte Moderna da Bahia: "Este nosso não é um Museu, o termo é impróprio: o Museu conserva e nossa pinacoteca ainda não existe. Esse nosso deveria ser chamar Centro, Movimento, Escola [...]" (in Pereira, 2003).

Na sua dimensão clínica, a arte e suas instituições têm uma longa historia em assumir um papel de serviço social. Por exemplo, lidando com os impactos da segunda guerra mundial, o diretor de educação Victor DÁmico do MoMA em Nova York inaugurou The War Veteran's Art Center (1944 - 48) oferendo cursos e atividades expressivas facilitando o reajuste do veterano de guerra à vida civil. Arte aqui é vista como atividade terapêutica para um bem estar integral. Em paralelo, emergiram outras abordagens mais psicanalíticas onde o objeto de arte é mobilizado como parte do processo artístico-terapêutico ou constitui-se do próprio encontro entre o paciente e o terapeuta. Ali a potência da clínica "de pôr em relação", como anotam os psicólogos Eduardo Passos e Regina Benevides (in Fonseca e Engleman, 2004: 278), oferece um modo de fazer experimental artístico-clínico. Nos anos 1980 no Rio de Janeiro, o artista/psiquiatra Lula Wanderley instaurou um tal processo no Espaço Aberto ao Tempo dentro o hospital psiquiátrico Dom Pedro II (agora Instituto Municipal Nise da Silvera) efetuando "uma instituição na busca de uma psiquiatria poética" (in Mesa, 2018) - um modelo pioneiro 
da reforma psiquiátrica brasileira, ainda a ser mais criticamente apreciado no campo da arte.

É claro que os modelos de laboratório, escola e clínica podem ser mesclados e/ou coexistir. Talvez, em sua genealogia compartilhada da industrialização do século XIX, contrariar um modo com outro é uma maneira de difundir sua rigidez e suas normas. Re-conectar-se com as histórias que desafiaram, mesclaram e transitaram entre estes modos e as fronteiras de arte e vida tais como a Unidade Experimental ou o Museu-Escola de Lina Bo Bardi ou Espaço Aberto ao Tempo - no sentido genealógico de Foucault como uma investigação experimental - pode nos levar a imaginar novas possibilidades futuras.

Nestas recuperações também vibram outras ressonâncias dos contextos subterrâneos, como diz Oiticica, que assumiram sua geografia e limites como força geradora (Small, 2016: 119). Seja na conceituação do afeto catalisador da Dra. Nise da Silveira no seu trabalho com pacientes schizoprenicos do hospital psiquiátrico Dom Pedro II nos ateliês de pintura com o artista Almir Mavignier no final da década de 1940, ou dos legados pós neconcretos ou das pegagogias alternativas dos anos 1960 e 1970 e sua leitura do mundo antes da palavra Freireana, podemos ver um abrir-se ao outro como prática artística-pedagógica-clínica. Como diz o filósofo Enrique Dussel sobre a teologia da libertação, esse paradigma é uma praxis radicalmente política, que deliberadamente escolhe não ter como ponto de partida referências teóricas mas "o estado de coisas como elas realmente existem" (2003: 21). Também, como anota Rivera em relação ao movimento neoconcreto, este devir pelo mundo é um avançar da arte em si mesma como "uma produção de conhecimento", a propósito de "questões fundamentais à arte assim com à vida e à filosofia" (2013: 206).

O que podemos aprender ou desaprender se assumíssemos a potência deste devir pelo mundo? As últimas décadas testemunharam uma nova geração de profissionais buscando explorar esta questão e posicionando-se dentro e fora das instituições, ou melhor, como micro modalidades de luta dentro da instituição geral da arte, no que o filosófo Gerald Raunig (2009: xviii) descreveu como "práticas instituintes" - uma forma de trabalhar que frustra as lógicas de institucionalização, mas abraça um processo permanente de constituição (usando a noção de Antonio Negri do poder constituinte). A curadora Maria Lind descreve esse trabalho utilizando 
seu conceito do "the curatorial" (2011): uma curadoria que procura diferenciarse de "business as usual" e constitui uma forma de trabalhar que desafia o status quo para incorporar e/ou mobilizar vários formatos além da exposição (tais como seminários, comissões, publicações, educação) e também serem executados a partir de várias posições dentro do ecossistema da arte (curador, editor, assessor de imprensa, educador).

Estas formas de curadoria reconheciam a natureza fragmentada da esfera pública, na qual, como observa o crítico Simon Sheik, "fazer com que as coisas se tornem públicas é também uma tentativa de criar um público" (in Pérez-Barreiro e Camnitzer, 2009: 80). Se, então, interpretamos, como o historiador de arte Terry Smith sugere (2015: 34), a curadoria como uma prática de "tornar público" justamente com a diversidade de formato de Lind, abrimos possibilidades para uma curadoria que se reconfigura tanto nas abordagens de conteúdo quanto nos modos de endereçamento. Uma curadoria ao avesso então poderia ser imaginada, ao contrário de projetos feitos para um público a ser convocado, com uma construção constituinte com públicos - ao invés de um modelo linear, temos aí um nó gerador ${ }^{132}$.

Defende-se neste ao avesso uma práxis decolonial que pretende radicalizar as possibilidades deste nó gerador. Como indaga a pesquisadora Catherine Walsh sobre pedagogia: "o que significa pensar descolonização [curatorialmente] e a [curadoria] numa forma descolonial?" (2013: 31) Como isso pode ser abordado a partir de uma relação indissociável entre o conteúdo, processo, e modo de endereçamento? Visando uma práxis, como observa o artista Ricardo Basbaum na análise da linha orgânica de Clark, que opera como uma construção ganhando progressivamente "espessura", envolvendo mais e mais espaços, questões, elementos e conceitos, tornandose uma "membrana" de micropolítica, de contato e vazio produtivo (in Albero e Buchmann, 2006: 100). Nestes 'nós' ou "membranas", os modos de laboratório, escola ou clínica têm o potencial de energizar um ao outro por meio da incorporação de um sistema de linguagens e práticas trazidas para dentro de um outro. Aberto às estratégias de "ventilação", como Rivera (In Mesa 2018) anota em relação às práticas da clínica Foyer de L’Équipe na Bélgica, cria a possibilidade de instaurar agenciamentos transversais. 0 interesse em tais agenciamentos faz parte das mudanças das últimas

132 O curador/artista Mick Wilson (2011) sugera que concebemos a relação produção artística-esfera pública como um nó em fez de forma linear. 
décadas em direção às práticas coletivas, sociais e relacionais e pelo apetite polifônico e antagônico da contemporaneidade para as fronteiras ontológicas, novos devires e eventos. Nestes contextos construímos nossas potencialidades através da práxis - a realidade do ser-no-mundo, o potencial da atividade sensorial humana livre e da ação política concreta ${ }^{133}$. É um convite estar juntos no que Dewey (1934: 162) diria ser o trabalho da arte the work of art ('o obrar' da arte), em vez de a work (uma obra de arte) - uma transversalidade que permite "extrapolar linhas de fuga" (Lima/Pelbart, 2007: 732) dos modos predeterminados de laboratório, escola ou clínica, contaminando-se mutamente, forjando uma práxis política, livre e sensorial. Constitutivamente frágil, como Pelbart reflete em relação ao contemporâneo, é fundamentalmente uma práxis de "tentativa e erro, experimentação, fracassos, remontagens, recolagens a partir de destroços anteriores" (In Mesa, 2015).

\section{Cumplicidade e proximidade como posicionamentos político-poéticos}

Como fio emergente nestes laboratórios, escolas e clínicas, o cuidado surge diante a demanda por interfaces que possam agenciar pelo avesso dos grandes espetáculos, atuando pelas frestas, margens e heterotopias. Tanto zonas de risco, quanto zonas de potências emergentes, as curadorias ao avesso 'cuidam' de processos que reconfiguram outras possibilidades de atuação de arte enquanto dimensão crítica e força geradora.

No entanto, cuidar não é algum tipo de paternalismo benigno, nem uma obrigação ou fantasia terapêutica de igualitarismo. Trata-se de reciprocidade, isto é, de relação de contágio mútuo, o que não significa não haver dissenso ou questões de relações de poder desiguais, mas que se caracteriza, como observa a filósofa Nel Noddings (2013), por um afastamento da posição de eu centralizador (pode-se ler aqui os papéis tradicionais de curador, artista, educador ou instituição) para abrir-se ao outro como receptividade disponível, parcial (tomar partido) e ética (indivíduo, lugar, comunidade). Um 'abrir-se' que exige um trabalho entre e com artistas, públicos e contextos. Uma práxis que encarna o sentido original da palavra cumplicidade, em latin complicare significando dobrar juntos.

Nestes entres e dobras também demanda novas abordagens críticas.

\footnotetext{
${ }^{133}$ Aqui se juntando vários conceitos de práxis: "atividade livre na polis" (Aristóteles) entendido como parte de uma vida humana que é verdadeiramente livre; "atividade sensorial humana livre" (Marx) (in Bernstein, 1971: xiv/ 11); e "ação politica concreta" (Dussel, 2008:63).
} 
A teórica Eve Kosofsky Sedgwick examina o que ela chama de "drama de expor", que é o cerne de muita crítica (2003: 8). Sua abordagem explora uma crítica "reparativa" que evita o modo "detetive" de revelar o que está "abaixo" ou "atrás", ou se posiciona como um "além" em uma espécie de "gesto mandão". Ela sugere que talvez a noção de "beside" (ao lado) possa ser a preposição mais relevante para descrever sua busca por uma prática crítica diferenciada. A proposta de "posicionalidade irredutivelmente espacial" de Sedgwick é extremamente útil como uma provocação para pensar uma curadoria ao avesso que se desvia dos modelos hierárquicos para uma prática cúmplice e proximal de co-laborar no entre e com artistas, públicos e contextos. Em apoio às pessoas, organizações e questões sócio-eticas, este "beside" reposiciona conceitos e práticas de mediação de um meio supostamente neutro, auxiliando as partes ou mediando um discurso institucional numa relação arte-pública, para um conjunto de práticas e agenciamentos dentro, fora e além das instituições. Desafiando as dicotomias, também se opõe à distância que sempre corre o risco de reificar a crítica e demanda que mergulhemos nas complexidades como uma rede de relações, em todo o seu emaranhamento e fragilidade, não apenas como parte de, mas fundamental, tanto para o quê quanto para o como nós trabalhamos.

Uma prática do "beside" oferece ainda um rico paralelo à noção da teórica Irit Rogoff (2008) de produzir criticalidade através de "habitar" um problema, ao invés de analisá-lo, de modo que "o experiencial do que estamos vivendo é colocado em contato com o analítico". A tarefa é tornar-se visível, como uma espécie de espelho dentro do processo. Aqui, as estratégias de pesquisa-intervenção cartográfica, a partir das contribuições de Gilles Deleuze, utilizadas pelos psicólogos Eduardo Passos, Virgínia Kastrup e Liliana Escócia (2011), como meio de interagir no interior dos processos como eles estão se desenvolvendo, oferecem ferramentas úteis de método nãométodo, onde o cartógrafo ao invés de estar focado em algo em particular, está aberto ao inesperado devir "beside". Junto a estes métodos de cartografia, soma-se o trabalho do educador Fernand Deligny com crianças autistas e colaboradores em Cévennes no sul da França ao longo de três décadas, assumindo uma presença próxima como posicionamento de cuidado, observação, convívio e aprendizagem onde a "proximidade de outro não permite esquivança" (2015: 206). 


\section{Dispositivos de arte-ação: Arquivos comuns e clínicas de potência}

O registro da prática é o fio que vai tecendo a história do nosso processo. É através dele que ficamos para os outros [...] mas não basta registrar e guardar para si o que foi pensado [...] É fundamental a oferta do entendimento individual para a construção do acervo coletivo. Como bem pontuava Paulo Freire, o registro da reflexão e sua socialização num grupo são 'fundadores da consciência' [...] e também instrumentos para a construção de conhecimento (Freire, 2008: 55-60).

Como posicionamentos poético-politicos, a cumplicidade e proximidade também demandam outros modos de produção de conhecimento. $\mathrm{O}$ arquivo, por exemplo, como conceito e prática pode ser implementado tanto na afirmação quanto na subversão dos status quo, como anota a crítica Suely Rolnik em relação ao seu modelo de entrevistas sobre a obra de Lygia Clark: "seria interessante para os museus manterem sua função de construir arquivos de produção artística desde que sejam baseados em outro conceito de memória e o significado de sua construção" (in Borja Villel, 2009: 82). Mas podemos ir além e não apenas, como tem sido o caso, re-construir estas memórias através de releituras ou intervenções artísticas, curatoriais ou acadêmicas individuais, mas como um processo público e coletivo? E mais ainda, podemos imaginar, como Lula Wanderley sugere também em relação a Lygia Clark, sua obra e prática como um arquivo de futuro ${ }^{134}$, ativando o que Deleuze anotou, em sua invocação de Bergson, a função fabuladora da literatura e arte (1997: 133)? Repensar o arquivo como dispositivo sóciopolítico de devires e potências nestes sentidos parece uma ferramenta fundamental para uma curadoria ao avesso.

Manuel Borja-Villel, diretor do Museu Reina Sofia em Madrid, argumenta que o museu de arte do século XXI seja um "archive of the commons" (2011), se referindo ao uso compartilhado dos terrenos públicos na Inglaterra no seculo XVIII, agora entendido como recursos culturais e naturais acessiveis a toda a sociedade. Esse modelo abraça o museu contemporâneo como uma plataforma defensora para reconsiderar e retrabalhar o passado e histórias coloniais, através de práticas (por meio de exposições, estratégias de coleta e educação) e novos modelos de propriedade coletiva. Mas em contextos menos institucionalizados e mais precários, como construir tais plataformas comuns? E com públicos diversificados? Na prática, o que é o lugar do comum no 'commons'?

\footnotetext{
${ }^{134}$ Conversa com a autora, maio de 2019.
} 
Como uma possível resposta a teórica da performance Diana Taylor (2003) desafia a equação arquetípica da escrita = memória e seu depositar no arquivo, oferecendo "o repertório", onde tradições, performances e memórias encarnadas são transmitidas por ações ao vivo. No entanto, o repertório também sugere saberes e fazeres já conhecidos. O que faremos se o comum foi algo reprimido ou desvalorizado mas igualmente incorporado? E o incomum? É aqui que a clínica como dispositivo pode ser útil. Embora aliado ao discurso ocidental tanto como o arquivo e permeado pelo que Foucault denominou de "olhar médico" (1994), a clínica, no entanto, sugere um contexto empírico, relacional, investigativo e reparador, até "uma prática crítica do cuidado" como Rivera anota para a potência da clínica psicanalítica (in Mesa, 2018). A dimensão de serviço social afiliada aos atendimentos comunitários do uso de "clinic", em inglês, tais como "legal clinics" (literalmente clínicas jurídicas), oferece outras modalidades.

Ainda, pode-se acresentar o potencial subversivo da singularidade em meio à vida coletiva serializada, adotada por Felix Guattari e Jean Oury na clínica psiquiátrica LaBorde, na França, nos anos 1950 e 60 tais como as inversões de papel - equipe médica trabalhando como faxineiros, jardineiros, chefs e vice-versa. "O tratamento não é uma obra de arte" anota Guattari, "mas deve proceder do mesmo tipo de criatividade" (2009:192). Um exemplo do qual são as "tentativas" de habitar em rede de Deligny, convivendo com crianças autistas numa clínica aberta sem impor-Ihes regras e cartografando seus movimentos em arquivos de escritas, mapas e filmes, na busca de um espaço "comum" entre indivíduos radicalmente diferentes (2015: 151/153).

Reconfigurações singulares e coletivas da clínica e do arquivo podem ser o alfa e o ômega de uma práxis de curadoria ao avesso que se faz em público. Reinventam os contextos institucionais e também se liberam deles, como diz Pelbart e Lima em relação à clínica, "se faze[ndo] no território da cidade" (2007: 730) como dispostivos do comum e da potência. Seguem algumas reflexões em torno de três iniciativas recentes: uma intervenção coletiva de arte pública e plantas medicinais; o Projeto arte_cuidado e seus desdobramentos em revista e vídeo; uma performance de arte e loucura.

\subsection{Um pensar/praticar ecossistêmico: Farmácia Baldia de Boa Viagem}

A disputa no campo do simbólico é fundamental para disputar a cidade. O simbólico institui o real (Jailson de Souza e Silva in Mesa, 2014).

O projeto Farmácia Baldia da Boa Viagem foi realizado na ocasião da mostra 
"Sudário" do artista Carlos Vergara no Museu de Arte Contemporânea (MAC) de Niterói (dezembro 2013 - abril 2014). A exposição reuiniu décadas de viagens na forma de pinturas, fotografia e monotipias em lenços coletadas in loco, como impressos poéticos das singularidades do lugar. A Farmácia propôs outro tipo de viagem e recuperação análoga ao sudário, por meio de uma investigação tátil, curativa e coletiva das plantas medicinais que crescem nos terrenos comunitários e baldios ao redor do museu. O projeto, cujo nome faz menção à região do entorno do MAC, área que inclui a ilha histórica da Boa Viagem e a favela Morro do Palácio, transformou-se numa botânica política poética, resgatando a potência das proximidades despercebidas e chamando atenção para os recursos medicinais que se encontram em nosso 'quintal'.

Vergara concebeu a Farmácia Baldia como intervenção de arte pública pela primeira vez para Arte Cidade 3, realizado em São Paulo, em 1997. Mais de 16 anos depois, por ocasião de sua exposição no MAC, o artista pensou em (re)apresentá-la. Uma reunião inicial semelhante ao projeto em São Paulo foi realizada em outubro de 2013 concentrando-se num mapeamento das plantas medicinais da região com o artista, diretor/curador do MAC, botânicos e farmacologistas especializados em plantas medicinais e eu ${ }^{135}$. Um mês depois, numa onda contagiante de afetividade e confluências oportunas, o projeto tornou-se a Farmácia Baldia da Boa Viagem, inaugurando um coletivo de botânicos, educadores, artistas, produtores culturais, médicos, farmacologistas, administradores e agentes comunitários, restagando as iniciativas do Programa Arte Ação Ambiental do museu com o Morro do Palácio, especialmente suas colaborações com o Programa Médico Família (PMF) e o centro comunitário Macquinho, criado para ser um satélite do MAC na comunidade em 2008.

O coletivo investiu na idéia de um arquivo-clínico vivo. Isso se basearia tanto na expertise científica quanto no 'know-how' popular. O grupo mapeará e identificará plantas medicinais e seus diversos usos terapêuticos na área de Boa Viagem e, simultaneamente, procurará caminhos programáticos para tornar visível e promover esse conhecimento. Mais de 40 espécies foram identificadas. Doze grandes estandartes de bambu com tecidos de cores

\footnotetext{
${ }^{135}$ Luiz Guilherme Vergara (diretor/curador do MAC Niterói na época); Bettina Monika Ruppelt (especialista em plantas medicinais e professora de farmacologia da UFF), Leandro Rocha (também professor de farmacologia da UFF), Marcelo Guerra Santos e Luiz José Soares Pinto (professores de botânica das Universidades Estadual e Federal de Rio de Janeiro).
} 
vibrantes, classificados segundo o uso terapêutico, foram dispostos em diversos lugares onde as plantas estavam localizadas e um mapa/tabela com os nomes científicos e populares e usos terapêuticos foi apresentada na exposição de Vergara, junto com uma vitrine com amostras secas.

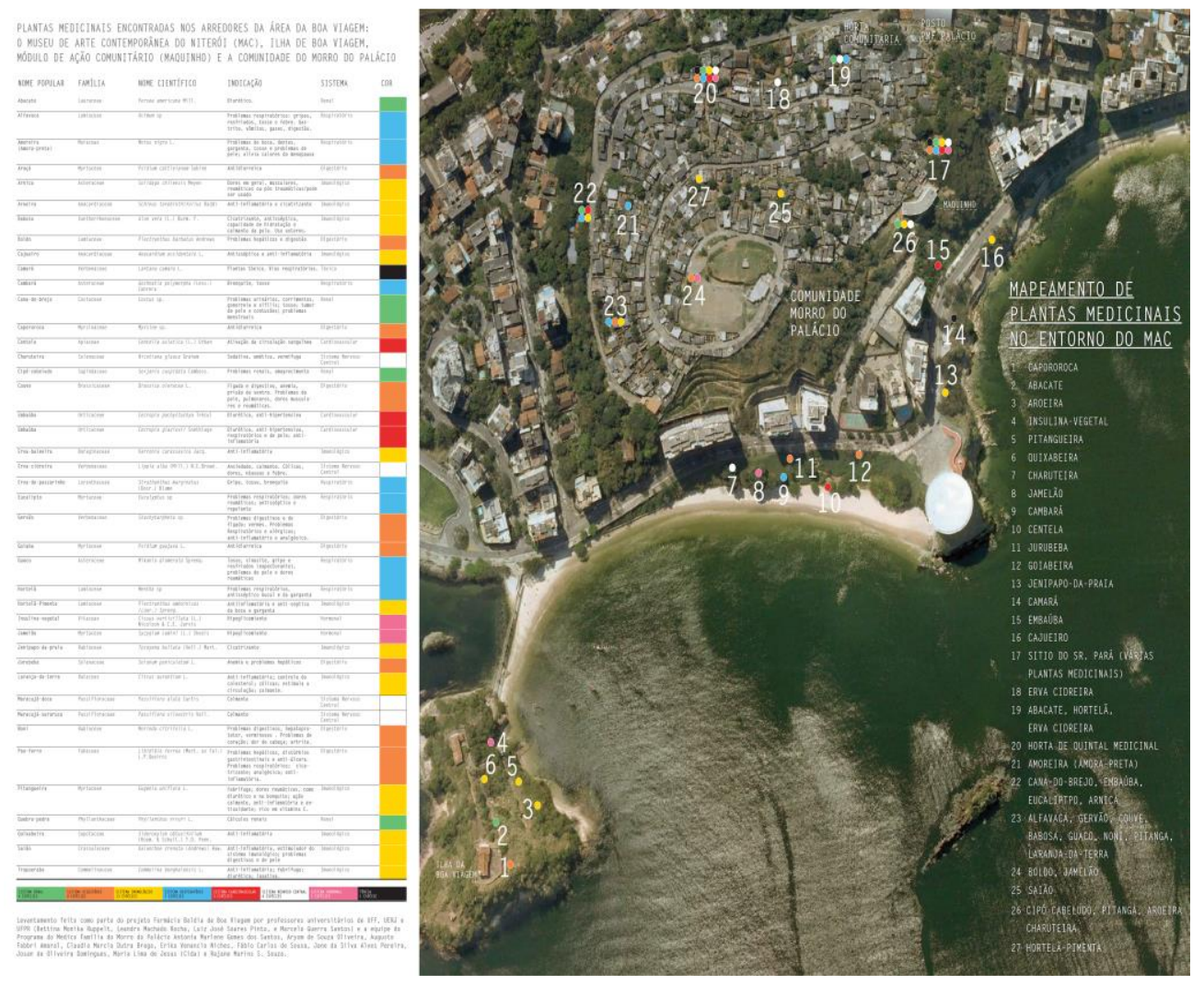

Figura II.6.1: Farmácia Baldia de Boa Viagem. Mapa/tabela das plantas medicinais identificadas na região de Boa Viagem, Niterói, 2014

Fonte: Realizado por Bettina Monika Ruppelt, Luiz José Soares Pinto, Marcelo Guerra Santos e o Programa Médico Família (Modulo Palácio) em especial Erika Venancio Niches, Fábio Carlos de Sousa, e Josan de Oliveira Domingues.

Além destes mapeamentos, criamos um programa de "Chás das cinco" em diversos locais da comunidade abrangendo conversas, trocas de receitas e aulas práticas. No final do projeto (mesmo buscando uma continuação) realizamos uma exposição de todo o processo - o mapa/tabela completo, fotos das plantas, reuniões e chás, retratos de senhoras da comunidade e suas receitas - apresentada no Macquinho, apesar das resistências da gestão política municipal, na época desvinculando o centro do museu e transformando-o em uma plataforma urbana digital. Um momento agridoce: finalmente o centro teria os recursos (pelos menos básicos) a funcionar, mas isto significaria a quase certeza de não-continuidade do projeto. $\mathrm{Na}$ inauguração da 'plataforma' em meio ao aproveitamento político e suas ambições tecnológicas, a exposição, feita por contribuições totalmente analógicas, incluindo botânicos, agentes de saúde, designers, produtores e 
membros da comunidade, permaneceu impotente, mas também, como uma semente de outra potência.

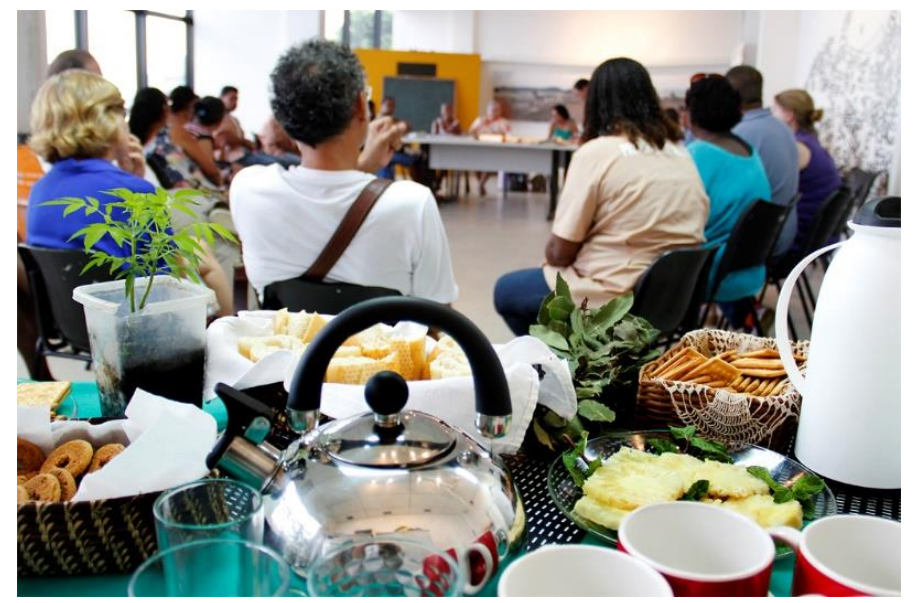

Figura II.6.2: Chá das cinco, encontro no Macquinho em janeiro 2014 Fonte: Joana Mazza.

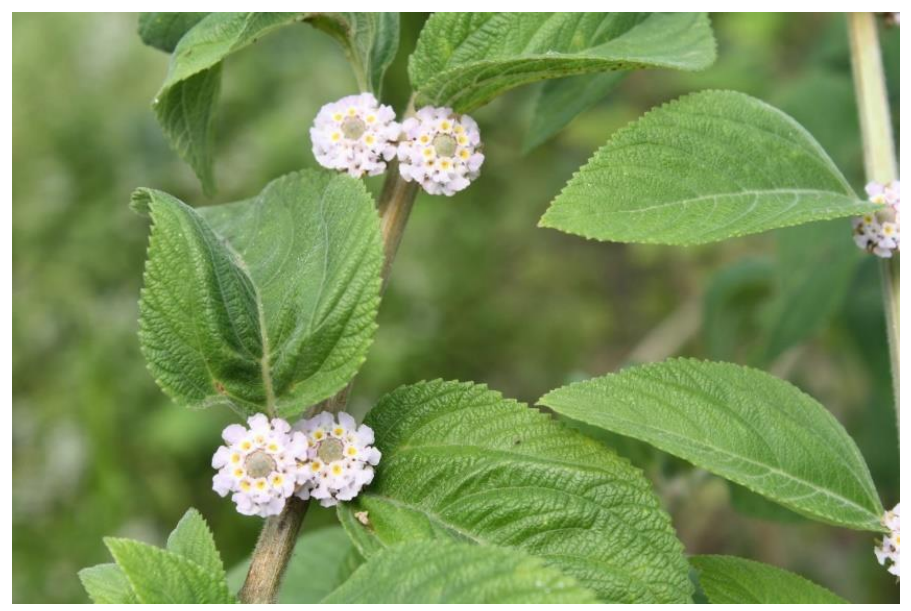

Figura II.6.3: Erva de cedeira Fonte: Marcelo Guerra Santos.

Assim como a artista Yve Lomax explora o ato de escrever interlaçado com o conceito de potencialidade em Giorgio Agamben, não reduzido a um binário potencial/atual mas sim como uma espécie de vivência e resistência no mundo (2009: 66), a energia do projeto da Farmácia parece ter sido sustentada pela potencialidade do que não aconteceu. A disfuncionalidade site specific, seja uma tentativa falida de um jardim comunitário ou o acúmulo de planilhas de propostas de captação, fez tanto parte quanto o que 'realmente' alcançamos. Nem arte nem cura, no processo precisávamos buscar outras lentes críticas para contemplar os esforços que 
estavam se desdobrando. Por exemplo, os pacientes psicóticos da comunidade com fobias dos espaços fechados participando num dos chás sem mal-estar ou crise. Ou a própria vontade, mesmo se fosse frágil, de se engajar neste processo artístico-pedagógico-clínico, em que bases de conhecimento e autonomias completamente diferentes estavam sendo catalisadas e consideradas dentro da mesma rede de indagações. O papel da arte aqui é modesto, como Vergara sugere, "algo a mais", mas também o "acordar a cumplicidade de fazer coisas"136 pode ser defendido como um novo radical, estimulando e, por vezes, alcançando um terceiro espaço - um denominador comum poético - entre os campos da botânica, medicina e saúde comunitária. Um dispositivo para conectar mundos.

\subsection{Cuidado como método: Projeto Arte_Cuidado}

Cuidar-se no grupo como forma de permitir e potencializar o que podemos. Cezar Migliorin (2019: 14)

Foi toda esta potência e falha que me acompanhou quando em 2016 me juntei à pesquisadora/curadora Izabela Pucu, na época diretora do Centro Municipal de Arte Hélio Oiticica (CMAHO), na coordenação da rede que chamamos Projeto arte_cuidado com diversos artistas, curadores, terapeutas, educadores e pesquisadores que atuam nas interfaces da arte com outros campos (saúde, meio-ambiente, ativismo social) ${ }^{137}$. O foco do projeto (ainda se desdobrando se menos ativamente) incluía pessoas envolvidas nas iniciativas em quatro territórios no Rio de Janeiro - Colônia Juliano Moreira, Engenho de Dentro, Centro e Boa Viagem (Niterói) - e organizações instituídas nestes lugares: Museu Bispo do Rosário Arte Contemporânea, Loucura Suburbana, Espaço Aberto ao Tempo, Museu de Imagens do Inconsciente, Centro Municipal de Arte Hélio Oiticica, Museu de Arte Contemporânea de Niterói e Macquinho. Contamos também com a participação dos programas de pós-graduação em Saúde Coletiva e em Estudos Contemporâneos das Artes da UFF, além de vários críticos, artistas, agentes e coletivos que se engajaram nestes lugares na época ou em tempos prévios. Tomando como central a ideia do cuidado como método, visamos o cuidado como fio que relaciona e entrelaça estas práticas e campos diversos. Assim, especialmente considerando a precariedade destes contextos,

\footnotetext{
${ }^{136}$ Entrevista, fevereiro, 2014.

${ }^{137}$ Para mais informação sobre o projeto e sua história, ver o editorial da Revista MESA (2018).
} 
procuramos formas de conectá-los de modo a registrar, compartilhar e refletir sobre este 'know-how' e no processo agilizar potências de produzir novos fazeres e saberes.

Ao longo de 2016 nos reunimos no intuito de refletir sobre estes interesses em comum e identificar possíveis iniciativas que poderíamos realizar juntos. Levantei o conceito de um arquivo comum, influenciado por pesquisas já listadas aqui, entre outras, e minhas próprias experiências profissionais. Nestas últimas especialmente: a co-edição com 0 pesquisador/curador Luiz Guilherme Vergara do periódico digital Revista Mesa na qual buscamos potencializar a revista como ferramenta de documentação, reflexão e colaboração; e o vídeo Coleta de múltiplas vozes realizado para o projeto de pedagogia expandida da $8^{\text {a }}$ Bienal do Mercosul compondo depoimentos de artistas, curadores, educadores e participantes da Bienal. Como modo de pesquisa-ação o vídeo realizou um convite à reflexão por meio de uma ouvidoria geradora, instaurada como uma câmera de ressonâncias dentro do próprio processo.

Propus para o Projeto arte_cuidado uma coleta em vídeo tanto para inventariar quanto para tornar público estes cuidados e cuidadores em forma de um arquivo comum. Como colaborador fundamental convidei o videógrafo Daniel Leão. Não visávamos o vídeo (eventualmente vídeos) Cuidado como método como um documentário no sentido tradicional, mas buscávamos utilizar a câmera, desde a filmagem inicial até a mostra em coletivo, como um dispositivo de ação-reflexão.

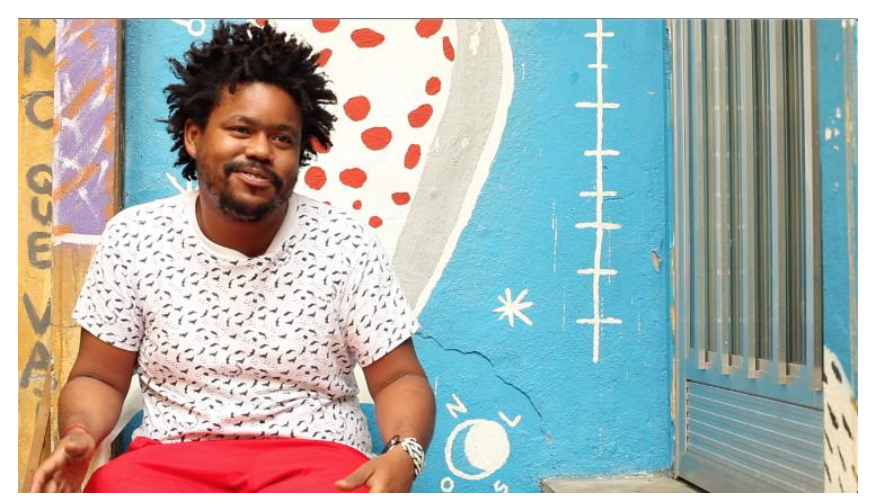

Figura II.6.4: Gê Vasconceles, Norte Comum, anota a falta de cuidado nas paralelos de exclusão e precariedade entre a loucura e questões raciais e de gênero Fonte: Frame: Cuidado como método, 2018. Dir: Daniel Leão e Jessica Gogan em colaboração com o Projeto arte_cuidado. 
Iniciamos o processo com um recorte/coleta de depoimentos realizados, a maioria em novembro de 2016, com alguns em janeiro 2017, nos quatro territórios já anotados. No final tivemos mais de 40 depoimentos, entre eles: o poeta Rafael Zacca, que avançou uma práxis de cuidado cultural que tratará menos "de bens culturais para voltar para um sentido de cultivo"; o músico Abel Luiz, que comentou que o lance do cuidado especialmente nos contextos asilares, historicamente criados para tirar pessoas do trânsito social, atua dentro deles para desenvolver "outros tempos e trânsitos" que poderão acabar "produzindo outras potências"; a artista Eleonora Fabião, que sugeriu a prática de performance como modo de suspender a ordem das coisas onde "estranhar é cuidar"; a ênfase dada pelo psicólogo Túlio Franco na importância do "cuidado de si" como fundamental para o processo de cuidado em saúde; ou o médico/ator Vitor Pordeus, inspirado no afeto catalisador da Dra. Nise da Silvera, que na sua mesclagem de cuidado e improviso defende "deixa[r] a natureza organizar o trabalho".

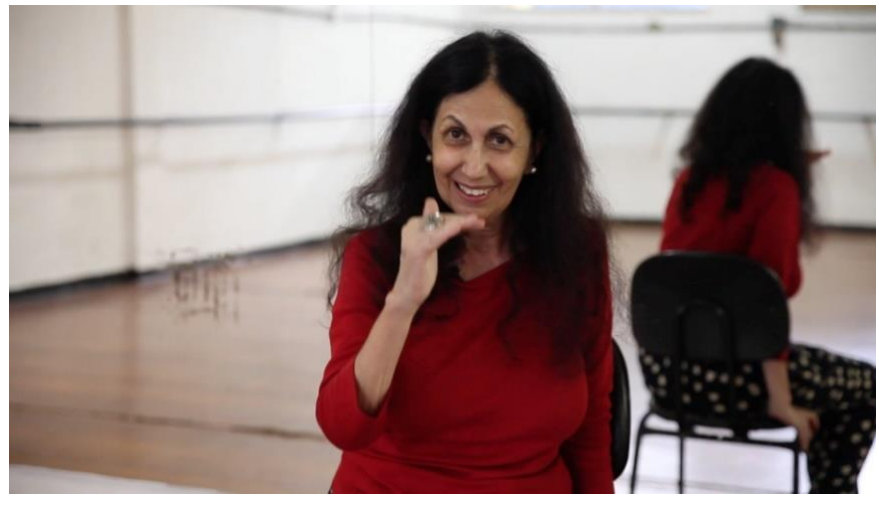

Figura II.6.5: Gina Ferreira, terapeuta, pergunta onde está o cuidado e onde está a arte Fonte: Frame: Cuidado como método, 2018. Dir: Daniel Leão e Jessica Gogan em colaboração com o Projeto arte_cuidado.

O projeto tinha o apoio fundamental do Museu de Arte do Rio (MAR) através do convite de Tania Rivera para apresentar o vídeo no âmbito de sua exposição "Lugares do delírio" (fevereiro - setembro 2017) e do Centro Municipal de Arte Hélio Oiticica (CMAHO) através das inciativas da Izabela Pucu tanto a partir da coordenação do Projeto arte_cuidado quanto para sua curadoria no CMAHO. Também contava com a realização do Instituto MESA e a colaboração das instituições, universidades e individuos envolvidos no Projeto arte_cuidado. Uma versão-rascunho foi apresentada no encontro público Cuidado como método \# 1 no CMAHO em dezembro de 2016 precedida de rodas de conversa com mais de 60 pessoas. No início de 2017 , a primeira edição com os depoimentos dos territórios Colônia Juliano Moreira 
e Engenho de Dentro com foco nas interfaces entre arte e saúde mental foi apresentada na "Lugares do delírio". Em 2018, realizarmos uma segunda edição, ampliando para questões de saúde em geral, o meio ambiente e outras institucionalidades incluindo vozes dos territórios do Centro e Boa Viagem, compartilhada num encontro com os entrevistados e colaboradores do Projeto arte_cuidado no MAR em dezembro 2018.

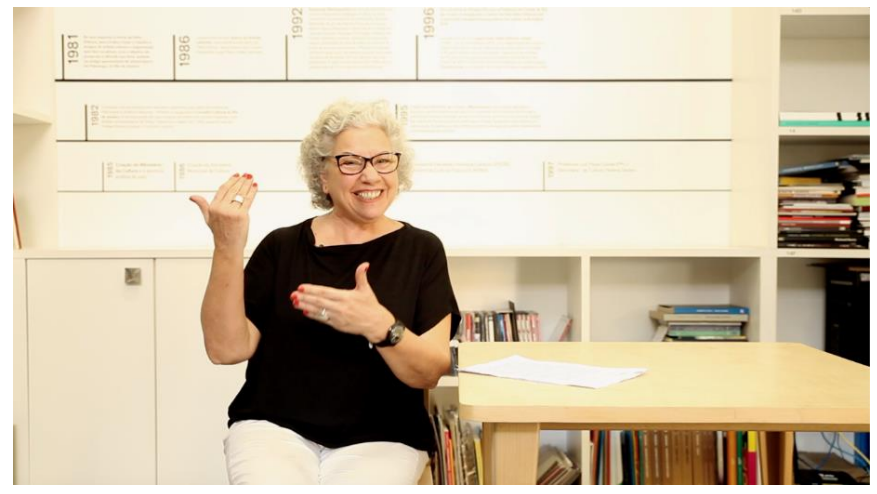

Figura Il.6.6: Glaucia Villas Bôas, socióloga, enfatiza a importância do cuidado em ampliar a laque das vozes envolvidas na pesquisa

Fonte: Frame: Cuidado como método, 2018. Dir: Daniel Leão e Jessica Gogan em colaboração com o Projeto arte_cuidado.

Ao avesso de roteiro predeterminado, o vídeo foi editado a partir do que inventariamos. Diferente do projeto Coleta das múltiplas vozes, realizado com um conjunto de pessoas comprometidas pela proposta da Bienal, o vídeo Cuidado como método inventariou práticas e pensamentos de quatros territórios e instituições bem distintas. Isso desafiou o processo consideravelmente. Como um arquivo comum buscamos ser ao mais representativos possível das pessoas envolvidas no Projeto arte_cuidado (e/ou indicadas por ele) mas ainda visando um vídeo que daria para assistir em uma única sessão. Com muita vontade e pouco recurso, isso criou uma tensão impossível entre a necessidade de contextualizar as falas e o desejo de identificar o que atravessava e complicava estes cuidados. Optamos pela metáfora do colar de missangas, acolhendo os depoimentos em suas diversas complexidades e ternuras. Era tanto um registro fundador transversal do cuidado quanto um espelho de reticências para apontar reflexões críticas e coletivas. Também da filmagem inicial até a edição final ocorreram mudanças de gestão, a participação de novos atores e ressignificações dos processos e afetos. Uma coleta é sempre parcial, destinada às delimitações de seu próprio recorte.

É importante salientar que a última edição do vídeo accompanhou o processo de realizar a publicação especial de Revista Mesa "Cuidado como 
método" desenvolvida a partir do encontro internacional Cuidado como método \# 2, 2017 e co-organizada por mim e Izabela com parceiras internacionais e colaborações das pessoas e instituições envolvidas no Projeto arte_cuidado ${ }^{138}$. Incluindo estudos de caso, artigos, diálogos, intervenções, e um glossário, a edição visou apoiar a reflexão individual e coletiva sobre a natureza das práticas do cuidado em diversos contextos, tanto nas suas especificidades territoriais, quanto além delas, de modo a fortalecer esta construção frágil tecida a muitas mãos. E assim, em nosso devir precário e tentativa afetiva-coletiva continuarmos, como sugere 0 curador Antony Huberman em seu ensaio "Take Care", que não diga "respeito a como preparar explicações antecipadamente", mas proponha "seguir a vida de uma ideia, em público, com os outros" (in EIDahab et al, 2011:12).

\section{Ato e testemunho dobradiços: Trêsformance de Arlindo}

Nosso coração...

60 minutos por segundo...

Meu coração dispara 60 minutos por segundo.

[...] É que nem relógio quando dispara.

Aquele relógio automático

Aí ele liga, aí ele vai lá e desliga.

Liga ele. Arlindo

Em sua clareza e delírio esta fala de Arlindo, colega e ex-companheiro de manicômio de Arthur Bispo do Rosário, se torna o título do video 60 minutos por segundo (2018) de Gustavo Speridão, baseado em sua residência artística (2016-2017) no Museu Bispo do Rosário Arte Contemporânea $(\mathrm{mBrac})^{139}$. Abrigando a coleção de Bispo do Rosário, o museu situa-se na Colônia Juliano Moreira, um complexo hospitalar e antigo manicômio localizado na periferia do Rio de Janeiro, onde Bispo esteve internado por quase 50 anos. O museu também administra o centro de convivência para usuários de saúde mental e suas famílias, chamado Polo Experimental, que inclui o Ateliê Gaia - um estúdio coletivo para artistas e ex-internos do antigo asilo - do qual Arlindo faz parte.

\footnotetext{
${ }^{138}$ Ver a ficha técnica da Revista Mesa (2018) para todos os envolvidos.

${ }^{139}$ Gustavo, Lívia Flores e Solon Ribeiro foram convidados por Rivera a realizar residências para "Lugares do Delírio". Em outubro 2017 Gustavo, Lívia e os artistas Daniel Murgel e Fernanda Magalhães, que também realizaram residências no mBrac, retornaram para o encontro Cuidado como método \# 2. Ver o estudo de caso sobre mBrac na Revista Mesa (2018).
} 
"A loucura do sujeito", como anota Deleuze, "corresponde ao tempo fora dos seus gonzos" (1997:39). Mas enquanto remete ao interminável controle, espera e desespero do tempo institucional, o "coração bate 60 minutos por segundo....", na sua espessura, também incorpora uma pulsação plena e dolorosa de luto/luta de potência que poderia transformar o passado traumatizado inextricavelmente entrelaçado como uma presença latente. Os relógios oferecem, na melhor das hipóteses, uma ficção conveniente, diz o neurocientista Daniel Eagelman.

Eles implicam que o tempo passa constantemente, previsivelmente para frente, quando nossa experiência mostra que muitas vezes faz o oposto: ele se estica e se comprime, pula uma batida e dobra de volta. (in Bilger, 2011).

No contexto de manicômio e lugares de sofrimento psíquico severos, precisamos de dispositivos que possam registrar e transformar estes pulos e dobras. Como anota a psicóloga Tania Kolker em relação às vítimas de tortura da ditadura no Brasil, precisamos assumir

o testemunho como um ato performativo, em que o dizer tanto descreve o que se passou, como dispara novos processos de subjetivação, o que se buscava era a oportunidade de ressignificar, desliteralizar e temporalizar aquilo que até então ficara suspenso no tempo e sem lugar na história (2018: 21) ${ }^{140}$.

Ressignificando sua memória do sistema asilar, Arlindo fez uma performance na antiga cela em que esteve internado com o Bispo. Sob o titulo Trêsformance, o artista Arlindo incorporou a figura do Bispo, a si mesmo e o guarda das celas do antigo Pavilhão 10, alternando papéis, momentos taciturnos, desepero, raiva, clamando por água de dentro e gritando para os presos de fora. $O$ ímpeto da performance se deu a partir do convite feito pelo encontro Cuidado como método \# 2 em colaboração com mBrac para que os artistas do Gaia protagonizassem as atividades na Colônia. Para esta ocasião Arlindo realizou seu "testemunho" como um ato performativo dobradiço convocando todos ali com um nó crítico-cúmplice ou "zona de vizinhança" (Deleuze, 1997:11) para seu devir - artistas, contexto, públicos, ex-internos e a equipe de mBrac.

\footnotetext{
${ }^{140}$ Agradeço Diana Kolker por apontar os paralelos entre o texto e a performance de Arlindo.
} 


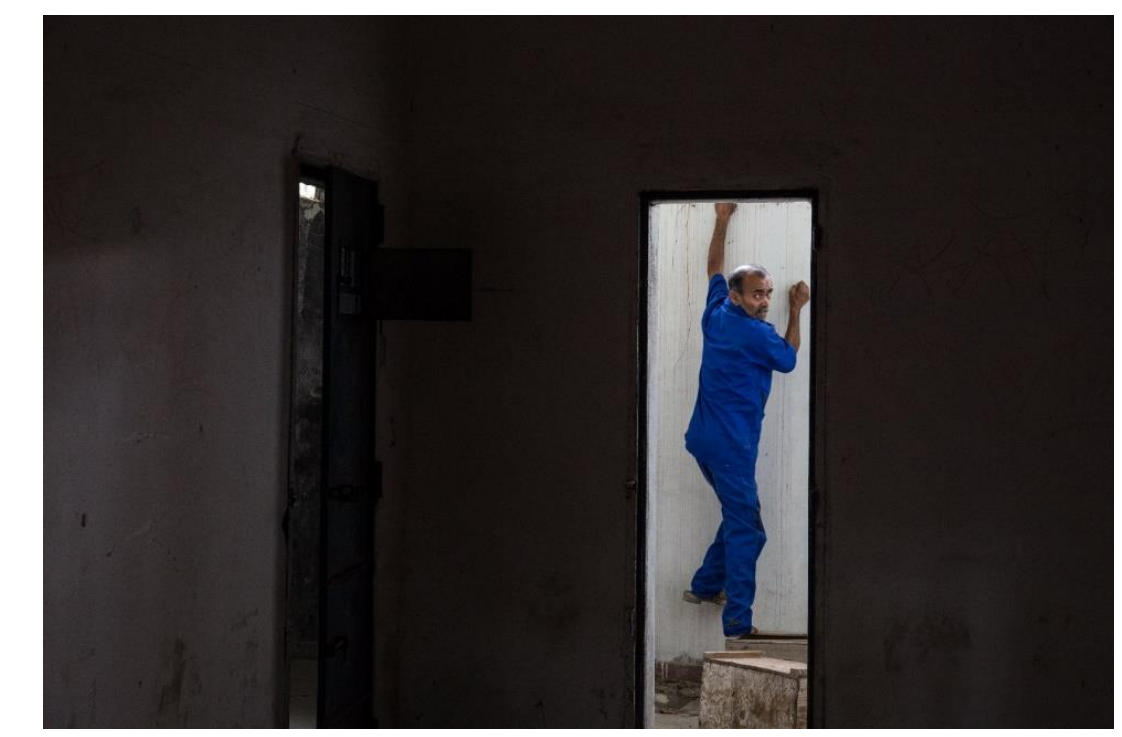

Figura II.6.7: Arlindo. Trêsformance. Cela antiga do Pavilhão 10, Ulisses Vianna, Colônia Juliano Moreira em outubro de 2017 Foto: Denise Adams.

Fazedor de assemblagens lúdicas de objetos e lixos quotidianos barcos, carros policiais, aviões entre outros - Trêsformance desdobrou uma nova dimensão de Arlindo como sujeito-artista. Mesmo influenciado por uma exposição que tratava a obra do Bispo como grande performance de vida (Resende in Mesa, 2018), a performance não tinha nenhuma tutela institucional. Mas ao confiar seus planos a Diana Kolker, gerente de educação do museu, que por sua vez teve o apoio da diretora Raquel Fernandes e do curador Ricardo Resende, demonstrou uma aposta no risco e cuidado singular da instituição. Um espaço-tempo de permissão que continua com Arlindo se repertoriando a si mesmo com mais versões da performance, sempre se inovando, tensionando e transbordando os limites terapêuticos e artísticos, entrelaçando novas testemunhas e colaboradores como se fosse uma clínica poética coletiva. Ao acompanhar este processo, Diana assume uma costura dobradiça como ato cúmplice - uma curadoria ao avesso - que fia, desfia e enfia, como a poeta Tamara Kamenszain observa em relação à escrita de mulheres, "pelo lado da bainha" $(2000)^{141}$. É pelo avesso que iremos entender os fios e infrastruturas que precisamos tecer e construir. Neste sentido a performance de Arlindo e sua curadoria ao avesso oferecem uma lente sobre o potencial das práticas de cuidado em contextos institucionais, uma arte que extrapola a clínica, uma clínica que extrapola a arte,

\footnotetext{
${ }^{141}$ Agradeço a Clara Araujo por me ter apresentado este texto.
} 
demonstrando as possibilidades criativas de um gesto(ão) ${ }^{142}$ coadjuvante, radical e afetivo.

"Que se fosse para o mundo..." é um devir artístico-pedagógico-clínico no avesso do "business as usual" nas relações artistas-obras-públicos. Mas, enquanto busca outros modos e praxes, como fita de Moebius, este devir opera menos contra ou anti instituições do que "inventar um uso menor da língua maior" (Deleuze: 1997:124) através de micro-ações criticas-geradoras dentro e fora de supostas oposições e mundos diversos, construindo e mobilizando novas relações. Nós, membranas e dobras que criam, ou melhor, urdiram potencialidades de vida, tentativas afetiva-coletivas e espaço-tempos de permissão; um arquivo-clínico comunitário de plantas medicinais no meio da monumentalidade da arte e das ambições políticas tecnológicas; uma rede de conexões tão precárias que sejam, para lembrar mesmo se for momentariamente, de nossas potências singulares e coletivas; e um convocatório ao um testemunho performativo. Ao conviver neste avesso, no seu trabalho cúmplice e proximal, o cuidado reside em tensionar os fios, como Pelbart sugere em relação ao conceito de jangada de Deligny (2013: 265), para que sejam suficientemente soltos para que eles não se soltem.

\section{Referências Bibliográficas}

Alberro, A. \& Buchmann, S. (Orgs.) (2006). Art after conceptual art. Vienna/Cambridge: Generali Foundation e The MIT Press.

Berstein, R. J. (1971). Praxis and Action: Contemporary Philosophies of Human Activity. Philadelphia: University of Pennsylvania Press.

Borja-Villel, M. et al. (Orgs.) (2009). 10,000 francs reward (The Contemporary Art Museum, dead or alive). Barcelona: Ministro de Cultura.

Braga, P. org (2008). Fios Soltos: Arte de Hélio Oiticica. São Paulo: Perspectiva

Deleuze, G. (1997). Crítica e clínica. São Paulo: Editora 34.

Deligny, F. (2015). O aracniano e outros textos. São Paulo: N-1 edições.

Dewey, J. (1934). Art as experience. New York: Perigee Books.

${ }^{142}$ Na sua contribuição para o Glossário da Revista Mesa (2018) o artista Enrico Rocha ofereceu o verbete "gestão com gesto". 
Dussel, E. (2008). Twenty Theses on Politics. Durham/London: Duke University Press.

Dussel, E. (2003). Beyond philosophy: Ethics, history, marxism and liberation theology. Oxford: Rowman \& Littlefield.

Eldahab, M. A. et al. orgs (2011). Circular fact. Berlin: Sternberg Press.

Escóssia, L., Kastrup, V. \& Passos, E. (Orgs.) (2011). Pistas do método da cartografia: Pesquisa-intervenção e produção de subjetividade. Porto Alegre: Sulina.

Fonseca, T. M. G. \& Engleman, S. (Orgs.) (2004). Corpo, arte e clinica. Porto Alegre: Editora UFGS.

Foucault, M. (1994). Birth of the clinic: An archaelogy of medical perception. New York: Vintage Books.

Freire, M. (2008). Educador, educador, educador. São Paulo: Paz e Terra.

Gogan, J. \& Morais, F. (2017). Domingos da criação: uma coleta do experimental em arte e educação. Rio de Janeiro: MESA.

Guarttari, F. (2009). Chaosophy: Texts and Interviews 1972 - 1977. Los Angeles: Semiotext(e).

Kamenszain, T. (2000). Histórias de amor y otros ensayos sobre poesia. Buenos Aires: Paidós.

Kolker, T. (2018). Agenciamentos ético-estético-políticos na reparação psíquica dos danos causados pela violência de Estado. In Ocupa Clínicas do Testemunho - a construção coletiva de uma política pública de reparação psíquica. Brasília: Ministério da Justiça, Comissão de Anistia; Rio de Janeiro: ISER.

Lomax, Y. (2009). Passionate being: Language, singularity, perseverance. London: I.B.Tauris.

Migliorin, C. (2019). Cinema e clínica: notas sobre uma prática (inédito).

Morais, F. (1979). Artes plásticas na América Latina: Do transe ao transitório. Rio de Janeiro: Editora Civilização Brasileira.

Noddings, N. (2013). Caring: A relational approach to ethics and moral education. Berkeley/Los Angeles/London: University of California Press.

Noever, P. N. (Org.) (2001). The Discursive Museum. Vienna: MAK/Hatje Cantz.

Obrist, H. U. \& Vanderlinden, B. (Orgs.) (2001). Laboratorium. Antwerp: DuMont.

Pelbart, P. P. (2013). Ao avesso de nilismo: cartografia de exaustão. São Paulo: N-1 edições.

Pereira, J. A. (2003). A didática dos museus de Lina Bo Bardi na Bahia e os conteúdos da modernidade e da identidade local $\left(1960\right.$ - 1964). In Docomomo $5^{\text {th }}$ Seminar, São Carlos, São Paulo, Brazil. http://www.docomomo.org.br. 
Pérez-Barreiro, G. \& Camnitzer, L. (Orgs.) (2009). Educação pela arte / arte pela educação. Porto Alegre: Fundação Bienal do Mercosul.

Raunig, G. R. \& Ray, G. (Orgs.) (2009). Art and contemporary critical practice: reinventing institutional critique. London: MayFlyBooks.

Rivera, T. (2013). O avesso do imaginário: arte contemprorânea e psicanálise. São Paulo: Cosac Naify.

Rivera, T. (2008). Ensaio sobre o espaço e o sujeito: Lygia Clark e a psicanálise. Agora, (Rio de Janeiro), v.XI, n.2.

Rogoff, I. (2008). Smuggling - an embodied criticality. European Institute for Progressive Cultural Policies. http://eipcp.net/transversal/0806/rogoff1/en

Sedgwick, E. K. (2003). Touching feeling: Affect, pedagogy, performativity. Durham/London: Duke University Press.

Small V., I. (2016). Hélio Oiticica: Folding the frame. Londres/Chicago: University of Chicago Press.

Smith, T. (2015). Talking contemporary curating. New York: Independent Curators International.

Taylor, D. (2003). The archive and the repertoire: Performing cultural memory in the Américas. Durham: Duke University Press.

Walsh, C. org (2013). Pedagogias decoloniales: Prácticas insurgentes de resistir, (re) existir, y (re) vivir. Serie Pensamento Decolonial.

\section{Outras Referências}

Bilger, B. (2011). The Possibilian: What a brush with death taught David Eagleman about the mysteries of time and the brain. The New Yorker, 25 de abril.

Borja-Villel, M. et al. (2011). Palestra Revisting the Late Capitalist Museum, conferência Now Museum, organizada pela CUNY, ICI e New Museum.

Clark, L. (1964). Caminhando 1963, Caminhando - Livro - Obra http://www.lygiaclark.org.br/arquivo_detPT.asp?idarquivo=17

Lind, M. \& Hoffaman, J. H. (2011). To Show or Not to Show, Mousse Magazine, no. 31. http://www.moussemagazine.it/articolo.mm?id=759\#top

Revista Mesa, http://institutomesa.org/RevistaMesa/edicoes.html Rio de Janeiro: Instituto MESA:

Revista Mesa \# 1 (2014). Territórios e práticas em processo.

Revista Mesa \# 3 (2015). Sentido de público.

Revista Mesa \# 5 (2018). Cuidado como método. 
Wilson, M. (2011). Palestra Artistas, Instituicões e esfera pública. In Reconfigurações do público: Arte, pedagogia, participação, organizado pelo Núcleu Experimental de Educação e Arte, Museu de Arte Moderna, Rio de Janeiro. 